\title{
LEKSIKOGRAAFILISE TARKVARA SKETCH ENGINE EESTI KEELE MOODUL
}

\author{
Jelena Kallas, Maria Tuulik ja Madis Jürviste \\ Eesti Keele Instituut
}

Kokkuvõte. 2010. aasta sügisel alustas Eesti Keele Instituut koos ettevõttega Lexical Computing Ltd. leksikograafilise tarkvara Sketch Engine (Kilgarriff jt 2004) eestikeelse mooduli väljatöötamist. Artiklis kirjeldatakse programmi põhifunktsioone. Põhjalikumalt käsitletakse funktsiooni Word Sketch (ee sõnavisand) võimalusi. Tutvustatakse sõnavisandite grammatika koostamise põhimõtteid, vaadeldakse eraldi substantiivide, adjektiivide ja verbide sõnavisandites esitatud süntagmaatilisi seoseid (st grammatilisi ja leksikaalseid kollokatsioone) ning arutletakse mooduli edasiarendusvõimaluste üle. Lisaks analüüsitakse, mil määral saab sõnavisandeid kasutada verbide lausemallide tuvastamisel.

Märksõnad: korpusleksikograafia, konkordantsid, sõnavisand, tesaurus, eesti keel

\section{Sketch Engine’i põhifunktsioonid}

2002. aastal loodud tarkvara Sketch Engine (SkE) $)^{1}$ on tekstikorpuste töötlemiseks mõeldud programm, mille põhifunktsioonid on konkordantside koostamine ja nende mitmekülgne töötlemine, korpusest sagedusloendite koostamine, korpusest automaatne sõnavisandite genereerimine ja distributiivne tesaurus (Kilgarriff jt 2004). Kokku on programmis esindatud 42 keele korpused. Tänapäeval kasutavad programmi sõnaraamatute loomisel sellised tuntud kirjastused nagu Oxford University Press, Cambridge University Press, Collins, Le Robert ja Cornelsen Verlag ja seda rakendati ka Dante leksikaalse andmebaasi (Atkins jt 2010) väljatöötamisel. Eestis kasutatakse prog-

1 Sketch Engine vt http://the.sketchengine.co.uk/auth/corpora/. Eesti Keele Instituut sõlmis lepingu 2010. a. sügisel. 
rammi praegu üheköitelise seletava sõnaraamatu (Langemets jt 2010) ja eesti keele põhisõnavara sõnastiku (Kallas ja Tuulik 2011) koostamisel.

Programmi eestikeelse mooduli sisendiks on eesti keele koondkorpus $^{2}$ (u $250 \mathrm{mln}$ sõnet), mille OÜ Filosoft on morfoloogiliselt märgendanud, osaliselt ühestanud ja osalausestanud. Peale selle on kättesaadav ka eesti lastekeele korpus (u 400000 sõnet).

\subsection{Konkordantsid ja nende töötlus}

Konkordants on sõnavormide loend koos nende tekstilise ümbrusega. Konkordantse kasutatakse mitmes rakenduslingvistika valdkonnas, eelkõige leksikograafias (Atkins jt 2003: 252-253) ja keeleõppes (Kitsnik 2006: 97-98). Adam Kilgarriff (2009) nimetab korpuste tugevuseks just autentset keelt ja ülisuurt näidete arvu. Konkordantsitööriist pakub õppijale suuremat hulka valikuid kui sõnaraamatud, näiteks saab otsida eri parameetrite põhjal ja valida ka viisi, kuidas tulemusi kuvatakse. Sõnaraamatu puhul on õppijal endal valikuvõimalusi paratamatult vähem, kuna leksikograaf on juba ära otsustanud, mida iga sõna puhul teada on vaja.

Sketch Engine on oma olemuselt midagi korpuse ja sõnaraamatu vahepealset. Programmis saab konkordantse koostada sõnavormist, lemmast või fraasist lähtudes või programmi päringukeelt $^{3}$ kasutades. Konkordantsi põhisõnale (ingl keyword) klõpsates näeb seda sõna lauses koos laiema kontekstiga, mis kuvatakse sõnast vasakul ja paremal. Joonisel 1 on esitatud sõna armastus konkordants koos morfoloogiliste märgenditega (sõnaliik, lemma, muutevormi tunnus).

2 Eesti keele koondkorpus vt http://test.cl.ut.ee/korpused/segakorpus/. Korpuse märgendamise kirjeldust vt http://www.filosoft.ee/html_morf_et/ morfoutinfo.html

3 vt http://trac.sketchengine.co.uk/wiki/SkE/CorpusQuerying 


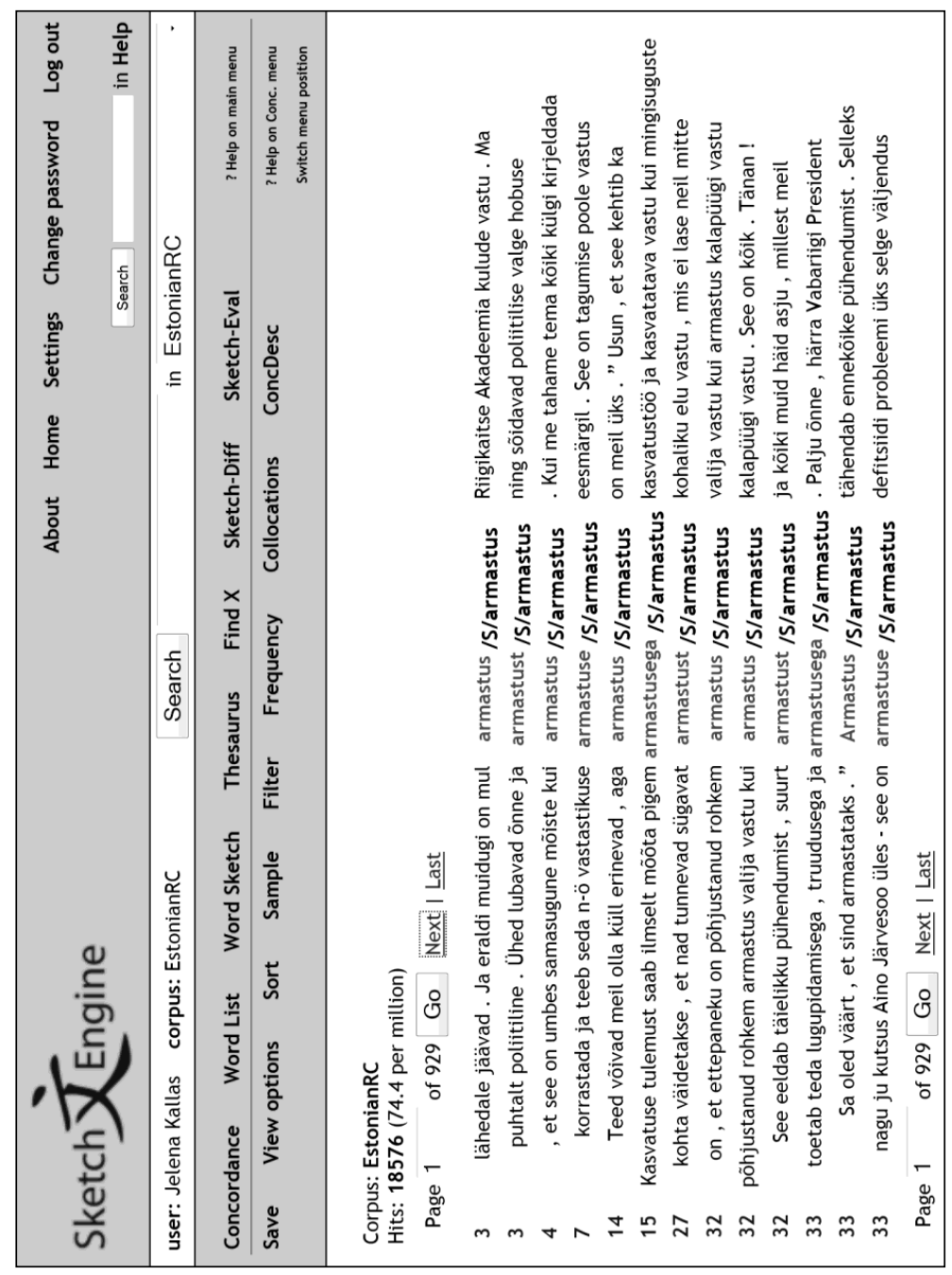

Joonis 1. Sõna armastus konkordants. 
Menüüst näeb konkordantside töötlemise võimalusi. Konkordantse saab salvestada (ingl Save) eri vormingutes, nt .txt- ja .csv-vormingusse. Vaate profiili (ingl View options) sätete muutmisega saab lisaks põhisõnale vaadata ka kõigi konkordantsides olevate sõnade morfoloogilisi märgendeid, saab määrata kuvatava konteksti pikkust ning konkordantsi ridade arvu. Kuna esialgu oli SkE loodud leksikograafide töövahendiks, siis prooviti parimate näitelausete valimist hõlbustada. Sel eesmärgil lisati Sketch Engine'isse aastal 2008 uus funktsioon nimega GDEX (ingl Good Dictionary Example) (Kilgarriff jt 2008). Eestikeelses moodulis on praegu GDEX-i nn vanilla-versioon, mis on keelest sõltumatu (olulisteks kriteeriumiteks on lause pikkus ning see, et lause alguses oleks suurtäht ja lõpus punkt, hüüumärk või küsimärk). Mitme keele jaoks on loodud ka keelespetsiifilised GDEX-i rakendused, mis arvestavad ka seda, mil määral sisaldub lauses konkreetse keele põhisõnavara (ingl core vocabulary). Vaate profiilis saab määrata, mitut parimat näitelauset soovitakse näha.

Sorteerimise abil (ingl Sort) saab konkordantse lahterdada põhisõna või parema ja vasaku naabri järgi. Sagedus (ingl Frequency) võimaldab koostada sagedusloendeid lähtuvalt põhisõna lemmast ja sõnavormist, nt saab teada, mis käändes esineb mingi substantiiv kõige sagedamini.

Erinevate statistikute abil (ingl T-score, MI, MI3, log likelihood, min. sensitivity, $\log$ Dice) saab otsida põhisõna kollokaate (ingl Collocates).

\subsection{Tesaurus}

Distributiivne tesaurus on funktsioon, mille abil saab automaatselt genereerida konkreetse lemma tesauruse. Tegemist ei ole semantilise andmebaasiga, mis keskenduks mõistele ja semantiliste suhete kaudu tema semantilisele väljale (vrd nt Vider 1999), vaid süsteemiga, mis toob statistika põhjal esile sõnu, millel on sarnane grammatiline ja kollokatiivne käitumine. Kuid siiski võib sarnast käitumist põhjustada ka samasse tähendusvälja kuulumine (nt armastus, kirg, sõprus joonisel 2). 


\begin{tabular}{|lrr|}
\hline \multicolumn{3}{l}{ armastus } \\
EstonianRC freq $=18576$ \\
\multicolumn{1}{|l|}{ Lemma } & Score & Freq \\
\hline$\underline{\text { ilu }}$ & 0.208 & 7174 \\
$\underline{\text { usk }}$ & 0.201 & 11245 \\
$\underline{\text { vabadus }}$ & 0.196 & 19110 \\
$\underline{\text { sõprus }}$ & 0.194 & 5372 \\
ônn & 0.192 & 29198 \\
$\underline{\text { kirg }}$ & 0.189 & 5126 \\
$\underline{\text { rõõm }}$ & 0.186 & 17878 \\
$\underline{\text { tunne }}$ & 0.184 & 29587 \\
lootus & 0.183 & 31330 \\
\hline
\end{tabular}

Joonis 2. Lemma armastus tesaurus.

\subsection{Sõnavisand}

Sõnavisand on automaatne üheleheline kokkuvõte sõna süntaktilisest ja kollokatiivsest käitumisest, mis tugineb korpusele (Kilgarriff jt 2004). SkE-s saab näha ühendit või konstruktsiooni moodustavate sõnade koosesinemiste arvu (ingl raw frequency). Kuid sõnadevahelise seose tugevuse mõõtmiseks on rakendatud ka esilduvust (ingl salience), mille annab logDice-statistik. Kristel Uiboaed (2010: 307) peab statistikute kasutamise eeliseks seda, et peale sõnade koosesinemise võetakse arvesse ka ühendit moodustavate sõnade eraldi esinemise sagedusi.

Sõnavisandi funktsiooni rakendamine eeldab seda, et oleks kirjutatud sõnavisandite grammatika (ingl Sketch Grammar), mis määrab, milliseid grammatilisi suhteid (ingl grammatical relations) programm otsima hakkab. Süsteem eristab grammatilisi suhteid, mille määrab sõnavisandite grammatika, ja alles seejärel mõõdetakse nende esinemissagedust ja esilduvust.

Sõnavisandite päringu kasutajaliideses toimub otsing lemma kaudu. Laiendatud päringuga (ingl Advanced options) on võimalik (vt joonist 3): 
- luua isiklik allkorpus (ingl Subcorpus), st valida olemasoleva korpuse failidest need, mis hakkavad kuuluma allkorpusesse;

- määrata suhte minimaalne esinemissagedus (ingl Minimum frequency);

- määrata grammatilise suhte minimaalne esilduvus (ingl Minimum salience);

- määrata ühe kategooria kuvatavate üksuste arv (ingl Maximum number of items in grammatical relations);

- sortida kollokaate esilduvuse määra või koosesinemiste arvu järgi (ingl Sort collocations according to salience/ raw frequency);

- kasutada funktsiooni "Tickbox Lexicography template", mis pakub eri kollokatsioonide kohta (GDEX-i sätete kohaselt) välja teatud arvu nn parimaid näitelauseid;

- klasterdada kollokatsioone (ingl Cluster collocations);

- määrata minimaalne sarnasus klasterdavate üksuste vahel (ingl Minimal similarity between cluster collocations).

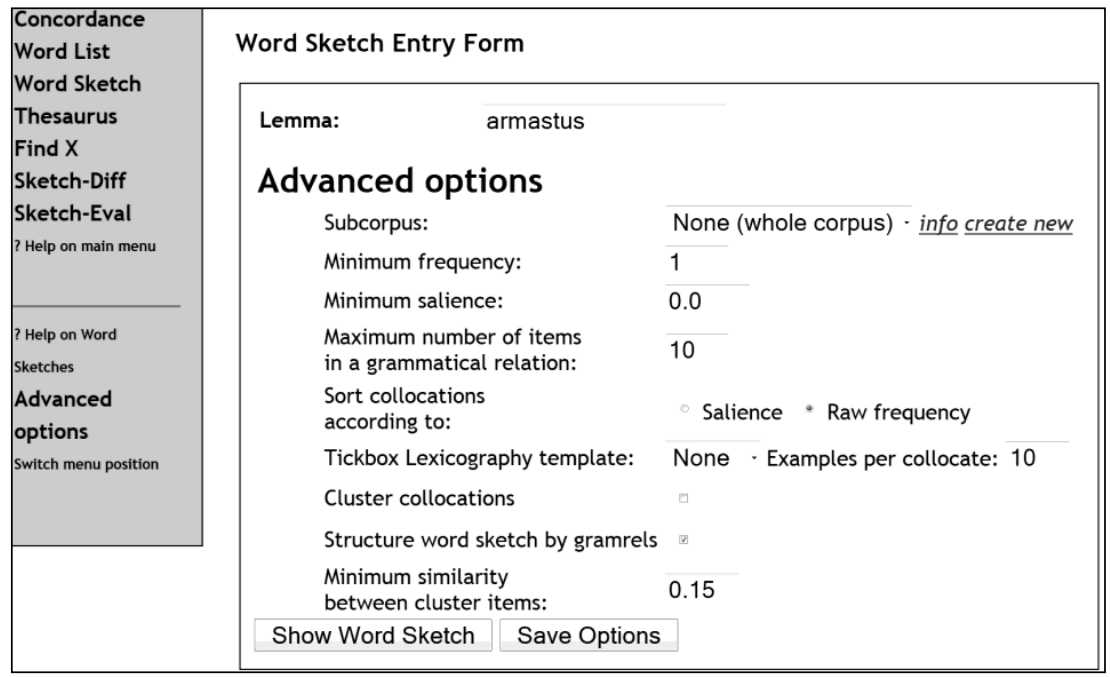

Joonis 3. Sõnavisandi kasutajaliides. 


\section{Eesti keele sõnavisandid}

Artikli teises osas tutvustame eesti keele sõnavisandite grammatika koostamise põhimõtteid ja näitame sõnaliikide kaupa süntagmaatiliste seoste esitamise printsiipe. Illustreerime ka sõnavisandite võrdlemise funktsiooni kasutust.

\subsection{Sõnavisandite grammatika koostamise põhimõtted}

Grammatika kirjutamise formalismiks on regulaaravaldised, mis põhinevad sõnaliigil ja muutetunnustel ${ }^{4}$. Lähtuvalt sõnaliigist ja muutetunnustest esitab süsteem sellised grammatilised klassid nagu grammatiline predikaat (öeldis), grammatiline subjekt (alus), grammatiline objekt (sihitis), predikatiiv (öeldistäide), adverbiaal (määrus). Grammatilistest seostest on keskendutud rinnastusseoste ja alistusseoste esiletoomisele. Rinnastusseostest toob süsteem esile konstruktsioonid sidesõnadega ja/või, kui/nagu. Alistusseostest esitatakse võimalike substantiivi, adjektiivi, verbi ja adverbi rektsioonistruktuuride enamik (vt lähemalt Kallas ja Tuulik 2011: 70).

Grammatilisi suhteid on sõnavisandite grammatikas nelja liiki (vt ka Svensén 2009: 416-418):

a) üheliikmeline suhe (UNARY) on defineeritud ühe konkreetse morfoloogilise kategooria kaudu ning see suhe annab infot ühe kindla grammatilise vormi kohta, nt mis käändes esineb konkreetse noomeni lemma kõige sagedamini;

b) sümmeetriline suhe (SYMMETRIC) puudutab eelkõige rinnastusseoses olevaid ühendeid (eesti moodulis on nendeks ja/või ja kui/nagu suhted);

c) kaheliikmelised suhted (DUAL) võimaldavad otsida kahe sõna ühendeid ja on määratletud kahe morfoloogilise kategooria kaudu (nt subjekt, objekt);

4 St noomeni arvu- ja käändetunnustel, võrdlusastmete tunnustel, verbi arvu-, isiku-, aja-, kõneviisi-, tegumoe- ja kõneliigitunnustel, samuti infiniitsete verbivormide tunnustel. 
d) kolmeliikmelised suhted (TRINARY) võimaldavad leida, millised nimisõnad esinevad substantiivi, adjektiivi ja verbi kaassõnafraasides, ja ühendverbide puhul nende laiendeid.

Sõnavisandite grammatika koostamisel on kasutatud ka „Eesti keele formaalses grammatikas” (Roosmaa jt 2001) kirjeldatud kitsendusi. Kokku on programmiga võimalik näidata 38 tüüpi grammatilisi seoseid. Peale selle võimaldab süsteem koostada ühendverbe moodustavate afiksaaladverbide ja verbi laienditega koos esinevate kaassõnade sagedusjärjestusi ning väljendverbide nominaalsete komponentide sagedusjärjestusi tingimusel, et nominaalne komponent on märgendatud kui „X”. (X-iga on märgendatud verbi juurde kuuluv sõna, millel eraldi sõnaliigi tähistus puudub, nt plehku.)

\subsection{Substantiivide sõnavisandid}

Substantiivide visandites tulevad esile sellised kategooriad nagu subjekt (mida $\mathrm{X}$ teeb?), objekt (mida X-iga tehakse?), adjektiivatribuut (milline $\mathrm{X}$ on?) ja eri tüüpi aktantsed atribuudid, mille moodustavad ühelt poolt semantilised käänded ja kaassõnad, teiselt poolt genitiiv. Rektsioonistruktuuridest esinevad visandites käände- (usk kellesse-millesse), kaassõna- (viha kelle-mille vastu) ja tegevusnimerektsioon (tahe mida teha). SkE abil saab mingil määral vaadelda ka sõna paradigmaatilisi tähendussuhteid, näiteks atributsiooni (hall, valge hiir), meronüümiat (auto rool, mootor, ratas) ja komplementaarseid vastandusi (poiss ja tüdruk), kuna seotud lemmad on tihtipeale kollokatsioonidest väljanopitavad. Allpool on esitatud substantiivide päike ja usk sõnavisandid.

Päikese sõnavisandis esinevad sellised kategooriad nagu subjekt (päike paistab, loojub, särab...), objekt (päikest nautima, võtma), adjektiivatribuut (loojuv, tõusev, lõõskav päike), genitiivatribuut (päikese loojumine, kiir, aktiivsus), aktantne atribuut (päikese käes) ja otsitava sõnaga rinnastusseoses olevad substantiivid (päike ja vihm, päike ja kuu...). Programm 


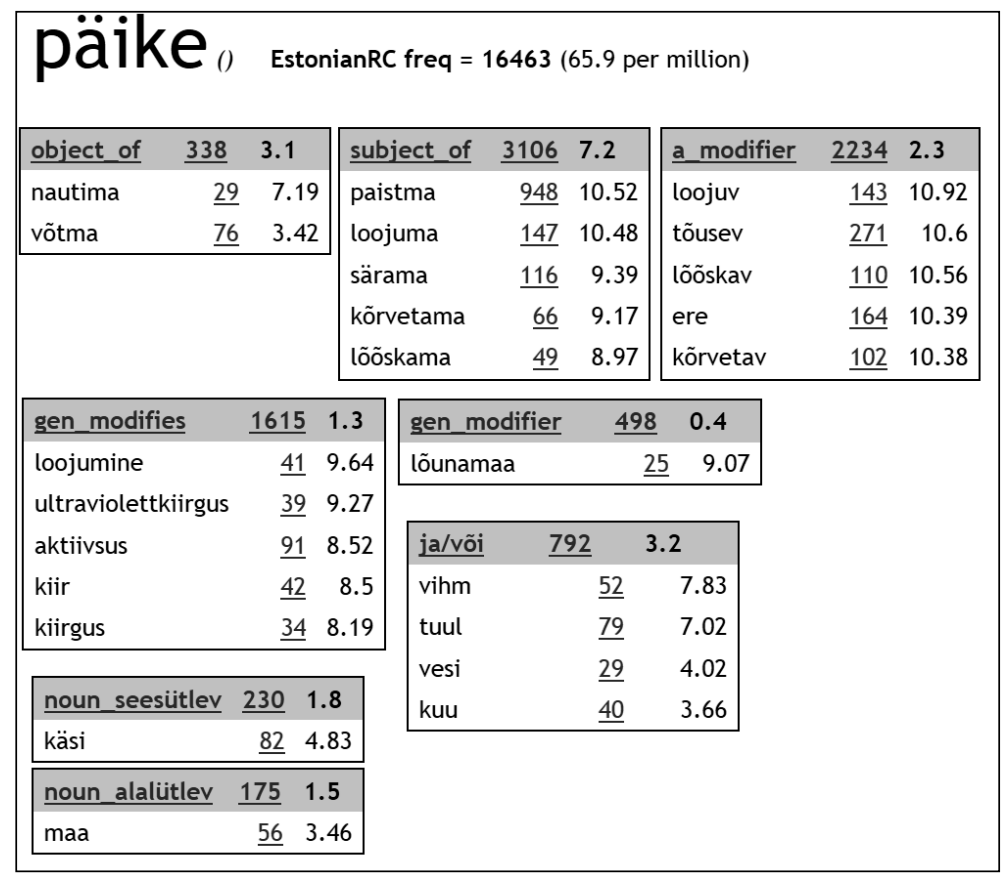

Joonis 4. Substantiivi päike sõnavisand.

näitab iga üksuse juures ka koosesinemiste arvu ja esilduvuse määra.

Usu sõnavisandis tulevad esile subjekt (usk kaob, puudub, aitab...), objekt (usku kaotama, sisendama, andma...), adjektiivatribuut (hea, kindel, uus usk ...; katoliku, luteri, vene usk...), genitiivatribuut (usu põhimõte, esindaja, puudumine....), öeldistäide (usk on oopium...) ja otsitava sõnaga rinnastusseoses olevad substantiivid (usk ja lootus, usk ja rahvus...).

Süsteem käsitleb atributiivset suhet kaheliikmelise paarina, seega esitatakse mõned ühendid puudulikult (nt usu kirik), kuna neil on veel omakorda laiendid, mis jäävad visandist kõrvale (luteri usu kirik). Kollokatsiooni kasutusjuhud koos kontekstiga avanevad koosesinemisarvu alt. 


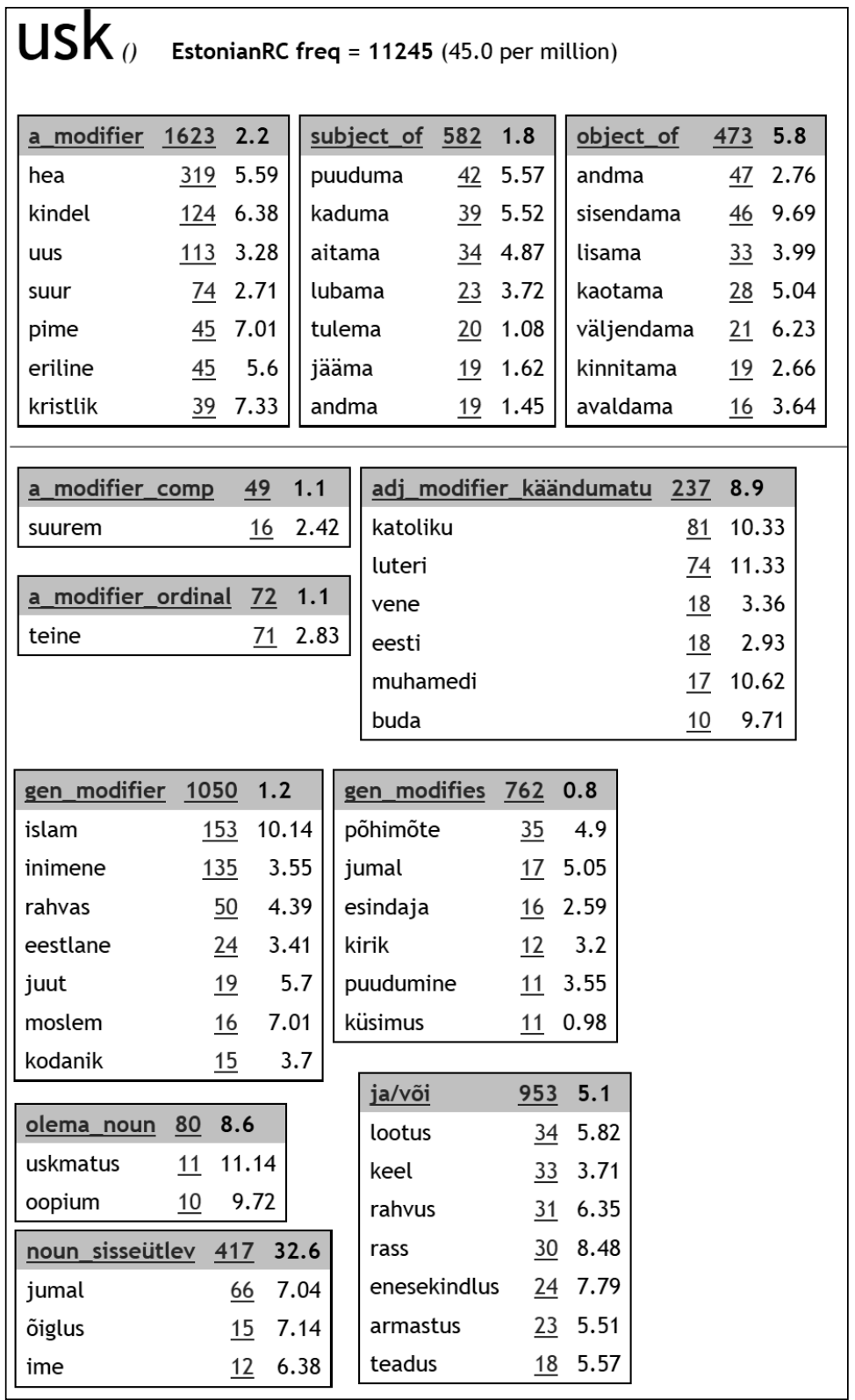

Joonis 5. Substantiivi usk sõnavisand. 


\subsection{Adjektiivide sõnavisandid}

Adjektiivifraasi laiendiliikmeks võib olla a) substantiiv(ifraas); b) kaassõnafraas: c) infinitiiv(ifraas); d) adjektiiv(ifraas), e) kvantorifraas; f) adverb(ifraas), g) kõrvallause (EKG 1993: 130). Sõnavisandid näitavad substantiivi, kaassõnafraasi, infinitiivifraasi ja adverbi. Rektsioonistruktuuridest on esitatud käände- (kindel kelles-milles), kaassõna- (kade kellemille peale) ja tegevusnimerektsioon (julge mida tegema).

Toome näiteks adjektiivide hea ja rikas sõnavisandid.

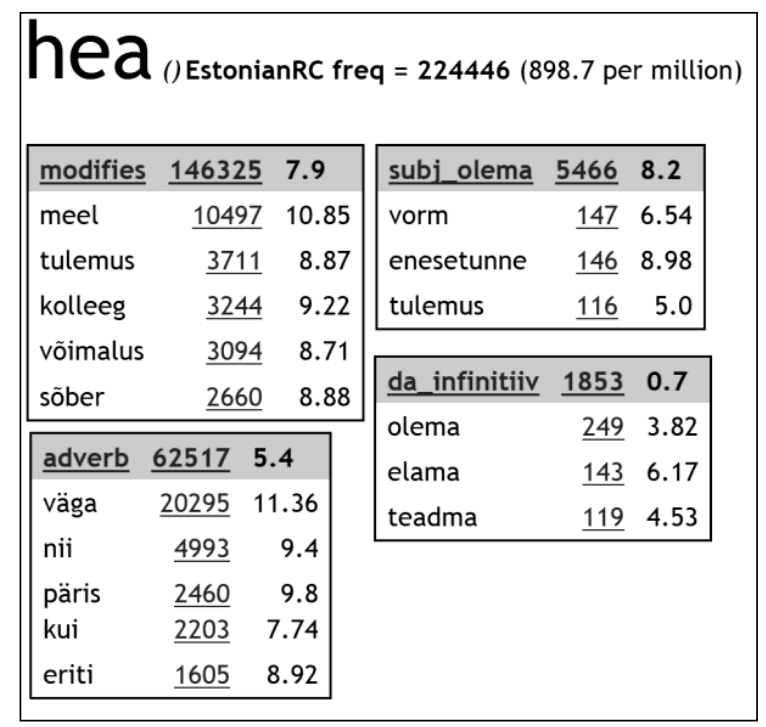

Joonis 6. Adjektiivi hea sõnavisand.

Lemma hea visandis tulid esile järgmised kategooriad: sagedasemad substantiivid, mille fraasis esineb hea adjektiivatribuudina (hea meel, tulemus, sõber...). Sellest võib järeldada, et hea meel on lemma hea sagedasem substantiiv+adjektiiv-tüüpi kollokatsioon. Sageduselt teisel kohal on adverbid (väga, päris, eriti hea...). Peale selle tulid esile predikatiiv (enesetunne on hea, vorm on hea, tulemus on hea) ja tegevusnimerektsioon (hea elada, hea teada, hea olla). 


\begin{tabular}{|c|c|c|c|c|c|c|c|c|c|}
\hline$\underline{\text { modifies }}$ & $\underline{4546}$ & 6.1 & & olema & $\underline{242}$ & 9.0 & adverb & 3872 & 8.3 \\
\hline riik & $\underline{665}$ & 5.95 & riil & & $\underline{13}$ & 0.29 & nii & $\underline{684}$ & 6.93 \\
\hline inimene & $\underline{469}$ & 5.34 & & & $\underline{7}$ & 2.28 & väga & $\underline{426}$ & 6.17 \\
\hline mees & $\underline{379}$ & 5.75 & ke & & $\underline{6}$ & 1.26 & kui & $\underline{262}$ & 4.94 \\
\hline maa & $\underline{139}$ & 4.74 & lin & & $\underline{6}$ & 0.28 & ka & $\underline{189}$ & 4.77 \\
\hline ärimees & $\underline{72}$ & 7.0 & ma & & $\underline{6}$ & 0.24 & ratsa & 152 & 10.27 \\
\hline pere & $\underline{67}$ & 5.21 & & & $\underline{4}$ & 1.11 & ainult & $\underline{121}$ & 6.81 \\
\hline naine & $\underline{65}$ & 3.88 & & aaed & $\underline{3}$ & 4.08 & vaid & 107 & 6.43 \\
\hline \multicolumn{5}{|c|}{ adjective_pp_poolest $\underline{57} \quad 4778.0$} & & & & & \\
\hline \multicolumn{3}{|c|}{ kaalium } & $\underline{3}$ & 7.45 & & & & & \\
\hline \multicolumn{3}{|c|}{ antioksüdant } & $\underline{3}$ & 7.22 & & & & & \\
\hline \multicolumn{3}{|c|}{ maavara } & $\underline{3}$ & 6.93 & & & & & \\
\hline \multicolumn{3}{|c|}{ loodusvara } & $\underline{3}$ & 6.76 & & & & & \\
\hline \multicolumn{3}{|l|}{ flavonoidi } & $\underline{2}$ & 9.46 & & & & & \\
\hline \multicolumn{3}{|l|}{ B-vitamiin } & $\underline{2}$ & 8.87 & & & & & \\
\hline \multicolumn{3}{|l|}{ kiudaine } & $\underline{2}$ & 7.51 & & & & & \\
\hline
\end{tabular}

Joonis 7. Adjektiivi rikas sõnavisand.

Lemma rikas visandis esinesid järgmised kategooriad: sagedasemad substantiivid, mille fraasis esineb rikas adjektiivatribuudina (rikas riik, inimene, mees...). Sageduselt teisel kohal on adverbid (nii, väga, piisavalt rikas). Lisaks tulid esile predikatiiv (riik on rikas, $\underline{\text { maa }}$ on rikas) ja kaassõnarektsioon (rikas mille poolest).

\subsection{Verbide sõnavisandid}

Verbide sõnavisandites toob süsteem peale subjekti ja objekti esile ka adverbiaale ehk määrusi. Rektsioonistruktuuridest on esindatud järgmised rektsioonid: objekti- (toetama kedamida), käände- (tutvuma kellega-millega), kaassõna- (võitlema 
kelle-mille vastu) ja tegevusnimerektsioon (tahtma mida teha, jätma mida tegemata).

Suur leksikograafiline probleem on aga ühendverbide esiletoomine ning nende süntagmaatiliste seoste selgitamine. Kuna afiksaaladverbid on märgendatud korpuses kui adverbid, siis koostasime EKSS-i ühendverbide põhjal sagedasemate afiksaaladverbide loendi ja lisasime selle sõnavisandite grammatikasse. Tulemuseks on see, et süsteem otsib korpusest ja esitab sagedusloendina ka iga verbi ühendverbe, samuti ühendverbide objekte ja adverbiaale. Teine eesmärk oli tõsta visandites esile, millised kaassõnafraasid laiendavad üht või teist verbi (nt hoolitsema kelle-mille eest). Neid suhteid oli võimalik määratleda kolmeliikmeliste kategooriate kaudu.

Toome näiteks verbide hoolitsema ja tooma sõnavisandid.

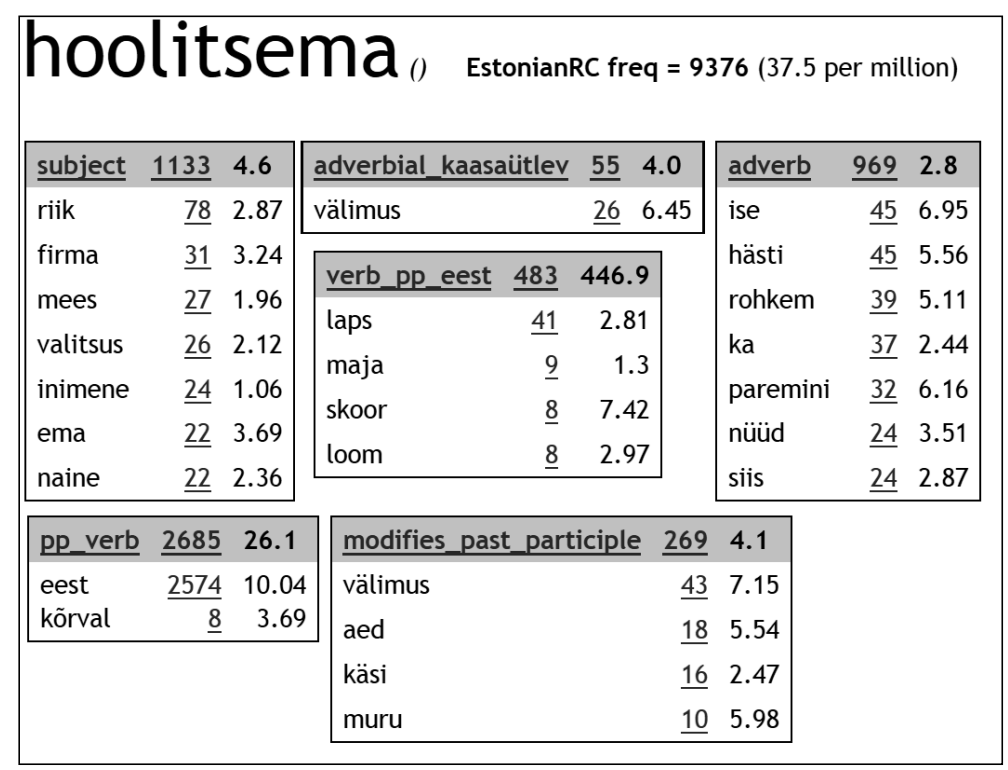

Joonis 8. Verbi hoolitsema sõnavisand.

Verbi hoolitsema visandis on näha sellised grammatilised klassid nagu subjekt (kes hoolitseb), sõltuvusmäärus (hoolitseb kelle eest) ja viisimäärus (kuidas hoolitseb). SkE tõi välja ka 
tud-partitsiibi sagedasemad kollokaadid (hoolitsetud välimus, aed jne). Nende grammatiliste klasside (uuritava verbi puhul subjekt ja adverbiaalid) alusel võib öelda, et sagedasemad laiendid on: kes (riik, firma, valitsus) hoolitseb kelle-mille eest (laste, inimeste eest) ja kuidas (hästi, korralikult).

\section{tOOMa () EstonianRC freq = 180229 (721.7 per million)}

\begin{tabular}{|c|c|c|c|c|c|c|c|c|}
\hline subject & $\underline{23212}$ & 5.5 & object & $\underline{6608}$ & 6.3 & adv ühendverb & $\underline{32416}$ & 21.6 \\
\hline aasta & $\underline{243}$ & 3.04 & näide & $\underline{840}$ & 7.07 & kaasa & $\underline{13557}$ & 12.09 \\
\hline tulevik & $\underline{223}$ & 6.42 & selgus & $\underline{177}$ & 8.76 & välja & $\underline{6604}$ & 9.63 \\
\hline päev & $\underline{221}$ & 4.81 & edu & $\underline{158}$ & 7.43 & esile & $\underline{3090}$ & 11.03 \\
\hline mees & $\underline{213}$ & 4.8 & kasu & $\underline{140}$ & 6.42 & sisse & $\underline{2959}$ & 10.24 \\
\hline inimene & $\underline{198}$ & 4.02 & & & & ära & $\underline{1899}$ & 8.4 \\
\hline naine & $\underline{117}$ & 4.56 & & & & tagasi & $\underline{1615}$ & 8.62 \\
\hline elu & $\underline{114}$ & 4.51 & & & & juurde & $\underline{659}$ & 8.29 \\
\hline
\end{tabular}

\begin{tabular}{|lrr|}
\hline adverbial sisseuitlev & $\underline{2875}$ & 13.4 \\
meel & $\underline{260}$ & 7.63 \\
kodu & $\underline{260}$ & 6.43 \\
haigla & $\underline{102}$ & 5.6 \\
\hline
\end{tabular}

\begin{tabular}{|lrr|}
\hline verb_pp_ette & $\underline{536}$ & 126.1 \\
\hline avalikkus & $\underline{149}$ & 7.84 \\
\hline
\end{tabular}

\begin{tabular}{|lll|}
\hline adverbial rajav & $\underline{413}$ & 24.5 \\
vaataja & $\underline{151}$ & 8.32 \\
\hline
\end{tabular}

\begin{tabular}{|c|c|c|c|c|c|}
\hline adverbial saav & $\underline{3414}$ & 20.8 & adverbial alaleuitlev & 6276 & 15.3 \\
\hline näide & $\underline{1571}$ & 8.0 & turg & $\underline{747}$ & 8.01 \\
\hline põhjus & $\underline{411}$ & 6.91 & lava & $\underline{374}$ & 8.01 \\
\hline põhjendus & $\underline{254}$ & 9.32 & päevavalge & $\underline{202}$ & 9.45 \\
\hline võrdlus & $\underline{164}$ & 8.88 & võitja & $\underline{165}$ & 7.11 \\
\hline lisa & $\underline{141}$ & 4.91 & koha & $\underline{161}$ & 5.08 \\
\hline ettekääne & $\underline{126}$ & 9.32 & ilm & $\underline{160}$ & 7.21 \\
\hline eeskuju & $\underline{125}$ & 7.74 & ekraan & 143 & 7.65 \\
\hline
\end{tabular}

\begin{tabular}{|lrr|}
\hline modifies_past_participle & $\underline{10399}$ & 9.1 \\
näide & $\underline{334}$ & 5.72 \\
tabel & $\underline{295}$ & 8.5 \\
andmed & $\underline{196}$ & 5.25 \\
väide & $\underline{180}$ & 6.49 \\
nõue & $\underline{115}$ & 5.83 \\
\hline
\end{tabular}

Joonis 9. Verbi tooma sõnavisand. 
Verbi tooma visandis on eristatud subjekt (kes toob), objekt (mida toob), adverbiaalid: 1) latiivne kohamäärus (tooma kuhu (adverbial_alaleütlev, adverbial_sisseütlev)); 2) latiivne valdajamäärus (tooma kelleni, kelle ette (adverbial_rajav; verb_pp_ette), sagedasemad on tooma vaatajani, tooma avalikkuse ette) ja 3) otstarbemäärus (tooma milleks (adverbial_saav), sagedasem on tooma näiteks). Seega verbi tooma sagedasemateks laienditeks on subjekt, objekt ja adverbiaalid, mis markeerivad sihtkohta, valdajat ning otstarvet. Peale selle näeb verbi tooma visandis ka sagedasemaid ühendverbe: kaasa tooma, välja tooma, esile tooma ja sisse tooma.

\subsubsection{Verbide sõnavisandid kui lausemallide tuvastamise vahend}

Kas SkE annab infot otseselt lausemallide kohta või pakub ta vaid sagedasemate laiendite tüüpe? Kas lisaks sõnasemantikale võimaldab visand saada aimu ka konkreetse verbi lausesemantikast? Kas võib oletada, et verbide visandites esile toodud grammatilised klassid (subjekt, objekt, määrus jt) võimaldavad rekonstrueerida verbiga tähistatud tegevussituatsiooni ja selle komponente?

Sõnatähenduse ja tegevussituatsiooni vahekorra üle on arutlenud Huno Rätsep (1978: 237-243), kes on tõdenud, et keeliti võivad tegevussituatsiooni komponendid lauses avalduda situatsiooni kesksest sõnast sõltuvates eraldi sõnades. Sellisel juhul on lause või sõnaühendi keskse sõna tähendus üldisem ja tegevussituatsiooni mõistele kõige lähedasem. Seejuures rõhutab Rätsep (1978: 241), et eesti keeles esitatakse tegevussituatsiooni komponendid pindstruktuuris eraldi sõnadena tegevussituatsiooni mõistet märkiva sõna kõrval.

Teiselt poolt arvatakse, et semantilisi rolle tuleb grammatilistest rollidest ehk lauseliikmetest lahus hoida, sest seost grammatilise käände ja semantilise rolli vahel ei ole ning nimisõna käändevormist ei saa kunagi üheselt järeldada tema semantilist vormi (vt nt Pajusalu 2009: 81-82). Siiski märgib Renate 
Pajusalu (ibid.), et kuigi semantilistel rollidel ei ole grammatilise vormistusega üksühest seost, pole vorm kunagi tähendusetu.

Allpool proovime lemma jalutama näitel rekonstrueerida konkreetse verbi tüüpilise lausemalli, toetudes sõnavisandi statistilistele andmetele. Seejuures eristame lausemalli tuletamisel järgmisi etappe: 1) semantiliste rollide tuvastamine grammatiliste suhete põhjal, mida sõnavisand ette annab; 2) rollide taga olevate entiteetide semantiline analüüs ja kategoriseerimine; 3) lausemalli tuletamine.

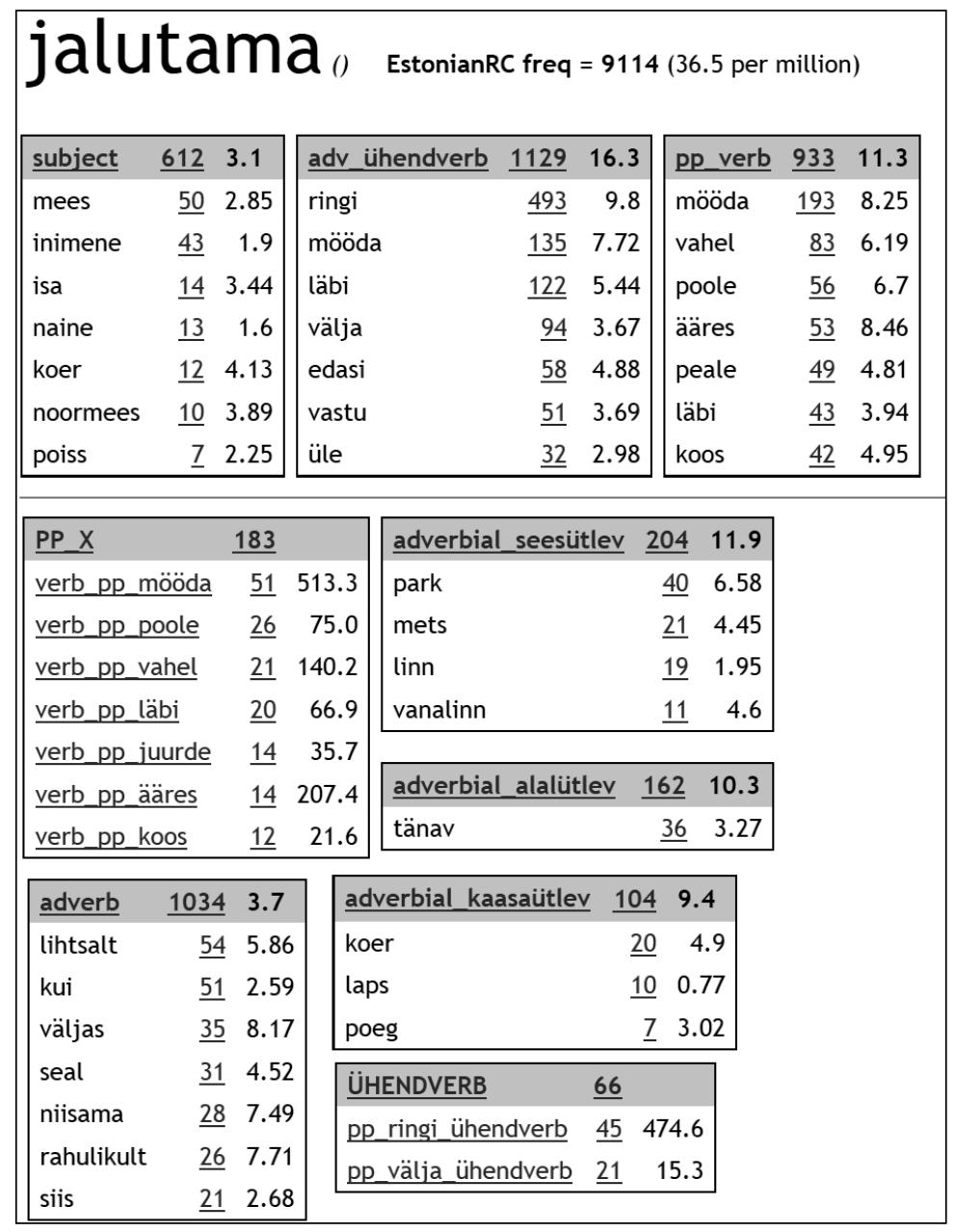

Joonis 10. Verbi jalutama sõnavisand. 
Sõnavisand aitab tuvastada eelkõige verbiga seotud sagedasemad grammatilised klassid, milleks on subjekt (612 esinemisjuhtu) ja eri tüüpi määrused: kaasnemismäärus (104 esinemisjuhtu); lokatiivne kohamäärus (204 esinemisjuhtu); latiivne kohamäärus, kuhu kuuluvad ka jalutama millegi äärestüüpi määrused; prolatiivne kohamäärus. Seega lähtuvalt esile tulnud grammatilistest klassidest võib selle verbi tegevussituatsioonis eristada järgmisi komponente ehk semantilisi rolle: AGENT, KAASLANE, KOHT, TEE.

Entiteetide analüüs kategooriate järgi näitab seda, et AGENDIKS on jalutama-verbi puhul enamasti inimene, harvem loom; KAASLASEKS on samuti elusolend, kas loom või inimene; KOHA sagedasemateks täitjateks on substantiivid park, mets, linn ja meri; TEED märkis sageli substantiiv tänav.

Niisiis on statistiliste andmete põhjal jalutama-verbi sagedasemad lausemalli komponendid AGENT, KOHT ja KAASLANE, seega võiks sõnastikus välja tuua vastavad verbilaiendid.

\subsection{Sõnavisandite võrdlus}

SkE lisafunktsioon Sketch-Diff võimaldab võrrelda kahe lemma sõnavisandeid. Eelkõige on see funktsioon mõeldud osasünonüümide võrdlemiseks ja eristamiseks. Süsteem toob esile sarnasusi ja erinevusi kahe semantiliselt seotud sõna süntagmaatilises käitumises, st esitab nii sõnade ühised kui ka vaid ühe sõnaga kokkukuuluvad kollokaadid. Näitena esitame katke komplementaarsete vastandite naine ja mees sõnavisandite võrdlusest (joonis 11).

SkE eristab kollokaate, mis kuuluvad sagedamini kokku lemmaga naine (näiteks rase naine, naine sünnitab, naist võtma), ja kollokaate, mis esinevad tihedamini koos lemmaga mees (näiteks tundmatu mees, meest sü̈̈distama, mees ja naine). Heledal taustal on atribuudid, mis esinesid enam-vähem võrdselt mõlema lemmaga. Erinevuste esiletoomisel arvestab programm ka sõnade üldist esinemissagedust korpuses. 


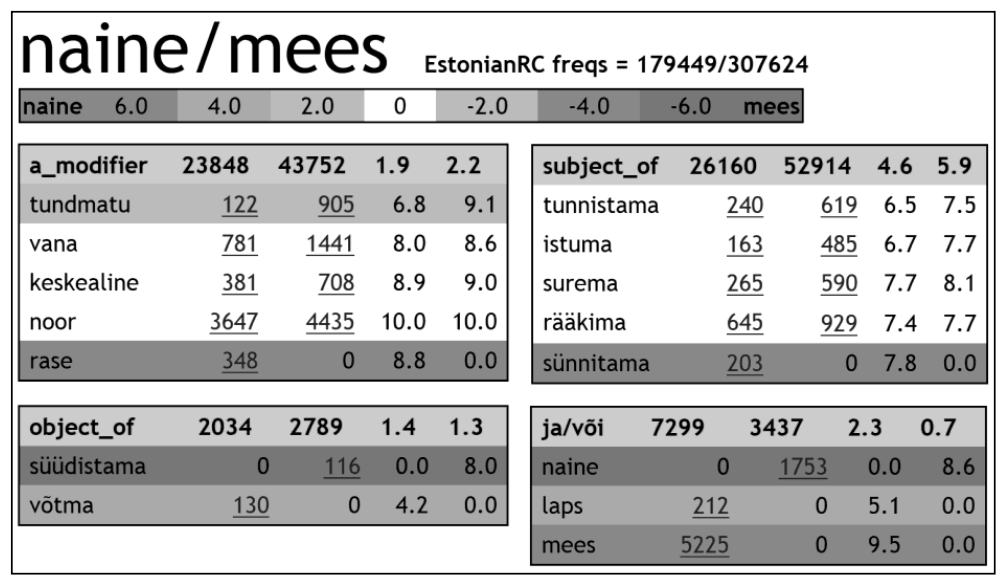

Joonis 11. Lemmade naine ja mees sõnavisandite võrdlus.

\section{Sketch Engine'i eestikeelse mooduli edasiarendused}

Sõnavisandite kvaliteet sõltub vahetult morfoloogilise ühestamise täpsusest. Praegu esineb morfoloogilise märgendamise vigu näiteks sõnaliikide tasandil ning käändsõnade puhul ka käände tasandil. Samuti on üldnimisõnadeks märgendatud isikunimesid (nt Pilv, Jänes, Rebane). Vigu tuleb ka sellest, et sisendkorpuse mitme tõlgendusega sõnade puhul jäi korpuse SkE jaoks ettevalmistamise järgus sisse ainult see tõlgendus, mis oli esikohal. Näiteks esialgu oli verbil kukutama kaks vormi: kukku+tama; $k u k u t a+m a$, kuid SkE-sse on jäänud neist vaid esimene.

Väljundit mõjutab oluliselt ka korpuse tekstide valik (koondkorpuses on praegu u 75\% tekstidest ajakirjandustekstid).

Seega tuleb Sketch Engine'it edasi arendades täiendada korpuse sisu ja parandada ühestamise kvaliteeti. Tulevikus võiks korpus olla rohkem tasakaalus ja seeläbi representatiivsem.

Teine arengusuund on sõnavisandite grammatika täiendamine ja selle metakeele (näiteks grammatiliste kategooriate nimetuste) lihtsustamine. Visandite kvaliteeti võiks parandada ka süntaktiliste märgendite kasutamine sõnavisandite gramma- 
tika kirjutamisel. See aitaks lahendada nt vaba sõnajärje probleemi. Tuleks püüelda ka semantilise ühestaja kasutamise poole, mida eesti keele jaoks praegu veel ei ole, kuid mida ingliskeelses Sketch Engine'is juba katsetatakse (McCarthy ja Reddy 2010).

Kuna sõnavisandid annavad ülevaate sõna süntagmaatilistest suhetest, saaks Sketch Engine'it edukalt kasutada eesti keele kui teise keele õppimisel ja õpetamisel. Sarnaselt õppesõnastikega toob SkE eksplitsiitselt esile sagedasemad rektsioonistruktuurid ja leksikaalsed kollokatsioonid ning aitab seega õppijat eelkõige just eestikeelse teksti koostamisel. Sõnavisandites näidatud rektsioonistruktuurid peaksid aitama vältida teise keele mõjudest tingitud vigu. Ingliskeelseid sõnavisandeid on juba proovitud automaatselt veebisõnastikuks pöörata (Hvelplund 2011). Tulemuseks on tavakasutajale lihtsasti mõistetav kasutajaliides, mis võimaldab sõnavisandeid vaadata elektroonilise sõnastiku vormingus. Sõnavisandite ja parimate näitelausete valimise funktsiooni kombineerides toimib SkE kollokatsioonide täisautomaatse sõnastikuna. Sellest lähtudes on meie eesmärk ka programmi eestikeelse mooduli veebisõnastikuks pööramine. Sellisel moel saadud n-ö automaatsõnastiku sihtgrupiks oleksid nii eesti keele kui teise ja/või võõrkeele õppijad kui ka tõlkijad, eesti keele uurijad ja kõik teised keelehuvilised.

\section{Kokkuvõte}

Artiklis tutvustasime leksikograafilise tarkvara Sketch Engine eestikeelse mooduli põhifunktsioone ja rakendamise võimalusi. Konkordantse ja sõnavisandeid saab kasutada eesti keele uurimisel ja kirjeldamisel, (elektrooniliste) sõnastike ja sagedusgrammatikate koostamisel ning eesti keele kui teise ja/või võõrkeele õpetamisel. Sõnavisandites tulevad esile eesti substantiivide, adjektiivide ja verbide sagedasemad süntagmaatilised seosed (rektsioonistruktuurid ja leksikaalsed kollokatsioonid), verbivisandeid saab kasutada ka lausemallide tuletamisel. Sketch Engine on üks esimesi eesti keelele kohandatud korpusleksikograafilisi programme, mille kasutajaskond 
ulatub leksikograafide hulgast väljapoole. Kuna korpuspõhisus on tänapäeva keeleteaduse levinumaid arengusuundi, siis on selliste programmide edendamine eesti keele uurimise seisukohast väga oluline.

\section{Aadress:}

Jelena Kallas, Maria Tuulik, Madis Jürviste

Eesti Keele Instituut

Roosikrantsi 6

10119 Tallinn, Eesti

E-mail: jelena.kallas@eki.ee,maria.tuulik@eki.ee, madis.jyrviste@eki.ee

\section{Kirjandus}

Atkins, Sue, Charles J. Fillmore, and Christopher R. Johnson (2003) "Lexicographing evidence: selecting information from corpus evidence". International Journal of Lexicography 15, 251-280.

Atkins, Sue, Adam Kilgarriff, and Michael Rundell (2010) "The DANTE database (Database of analysed texts of English)". Proceedings of the XII EURALEX International Congress (Leeuwarden, 6-10 July 2010), 167. Leeuwarden: Fryske Akademy.

EKG 1993 = Erelt, Mati, Reet Kasik, Helle Metslang, Henno Rajandi, Kristiina Ross, Henn Saari, Kaja Tael ja Silvi Vare (1993) Eesti keele grammatika II. Süntaks. Tallinn: Eesti Teaduste Akadeemia Keele ja Kirjanduse Instituut.

Hvelplund, Holger (2011) Using Sketch Engine with IDM's DPS for online dictionaries. Seminari materjalid <https://trac.sketchengine.co.uk/ wiki/SKEW-2/Program>. Vaadatud 01.05.2011.

Kallas, Jelena ja Maria Tuulik (2011) „Eesti keele põhisõnavara sõnastik: ajalooline kontekst ja koostamispõhimõtted". Eesti Rakenduslingvistika Ühingu aastaraamat 7, 59-75.

Kilgarriff, Adam, Pavel Rychly, Pavel Smrž, and David Tugwell (2004) "The Sketch Engine". Proceedings of the 11th EURALEX International Congress (Lorient, 6-10 July 2004), 105-117. Lorient: Université de Bretagne-Sud.

Kilgarriff, Adam, Milos Husák, Katy McAdam, Michael Rundell, and Pavel Rychlý (2008) "GDEX: Automatically finding good dictionary examples in a corpus". Proceedings of the XIII EURALEX International Congress (Barcelona, 15-19 July 2008), 105-117 . Barcelona: IULA, Documenta Universitaria. 
Kilgarriff, Adam (2009) "Corpora in the classroom without scaring the students". Proceedings 18th International Symposium on English Teaching. Taipei.

Kitsnik, Mare (2006) „Keelekorpused ja võõrkeeleõpe”. Eesti Rakenduslingvistika Ühingu aastaraamat 2, 93-107.

Langemets, Margit, Mai Tiits, Tiia Valdre ja Piret Voll (2010) „In spe: üheköiteline eesti keele sõnaraamat”. Keel ja Kirjandus 11, 793-810.

McCarthy, Diana and Siva Reddy (2010) Semantic tagging. Seminari materjalid <https://trac.sketchengine.co.uk/wiki/SKEW-2/Program>. Vaadatud 01.05.2011.

Pajusalu, Renate (2009) Sõna ja tähendus. Tallinn: Eesti Keele Sihtasutus

Roosmaa, Tiit, Mare Koit, Kadri Muischnek, Kaili Müürisep, Tiina Puolakainen ja Heli Uibo (2001) Eesti keele formaalne grammatika. Tartu: Tartu Ülikooli Kirjastus.

Rätsep, Huno (1978) Eesti keele lihtlausete tü̈bid. Tallinn: Valgus.

Svensén, Bo (2009) A handbook of lexicography: the theory and practice of dictionary-making. Cambridge: Cambridge University Press.

Uiboaed, Kristel (2010) „Statistilised meetodid murdekorpuse ühendverbide tuvastamisel". Eesti Rakenduslingvistika Ühingu aastaraamat 6, 307-326.

Vider, Kadri (1999) Sagedamad eesti verbid semantilises andmebaasis. Käsikirjaline magistritöö. Tartu: Tartu Ülikool. Eesti keele osakond.

Abstract. Jelena Kallas, Maria Tuulik, and Madis Jürviste: Esto-
nian language module of lexicographic software Sketch Engine. The Sketch Engine is a software aiming to analyse corpus data. Its main functions being the compilation and varied analysis of concordances, creating frequency lists, automatic compilation of word sketches and distributive thesauruses.

In the autumn of 2010 the Institute of the Estonian Language started to develop, in collaboration with Lexical Computing Ltd., the Estonian language module for the Sketch Engine software. The Estonian Sketch Engine consists of a 250-million word Estonian Reference Corpus.

The article gives an overview of Estonian Word Sketch grammar compilation principles. The authors demonstrate word sketches for nouns, verbs and adjectives. Also, an insight is given into the possibilities of further development of the Estonian language module.

The corpus-based approach being one of the most widespread tendencies in modern linguistics, it is of utmost importance for Estonian language research to promote the usage of programs such as the Sketch Engine.

Keywords: corpus lexicography, concordance, word sketch, thesaurus, Estonian 
